\title{
PERCEPÇ̃̃O DO USO DA NOTA FISCAL ELETRÔNICA (NF-e) POR PRODUTORES RURAIS DO MUNICÍPIO DE NOVA OLÍMPIA - MATO GROSSO
}

\author{
Valdemir Lino do Nascimento ${ }^{1}$ \\ Márcio Íris de Morais ${ }^{2}$ \\ Thiago Fernandes ${ }^{3}$ \\ Marcos Antônio da Silva Junior ${ }^{4}$ \\ Thaiany Fernandes 5
}

\section{RESUMO}

Este estudo consistiu em analisar a percepção na utilização da Nota Fiscal Eletrônica, denominada NF-e, junto aos produtores rurais situados no município de Nova Olímpia, Estado de Mato Grosso. Aplicou-se questionário por acessibilidade a amostra de quinze produtores rurais, a coleta de dados ocorreu durante o mês de fevereiro do ano de 2015. Os resultados da análise possibilitaram certificar que $100 \%$ dos produtores rurais entrevistados não utilizam o recurso da NF-e; 53,33\% não possuem recursos tecnológicos para a prática do procedimento; $60 \%$ revelaram que desconhecem a ferramenta NF-e, certificou-se também que $70 \%$ dos produtores responderam que não teriam dificuldade na utilização do processo para realizar a venda da produção, assim como, $80 \%$ dos produtores relataram que as informações acerca da NF-e poderiam ser fornecidas pelos prestadores de serviços contábeis.

Palavras-chaves: NF-e. Arquivo eletrônico. Tecnologia.

\section{ABSTRACT}

This study was to analyze the perception on the use of electronic invoices, named NF-e, along with farmers located in the municipality of Nova Olímpia, Mato Grosso state. Applied questionnaire for accessibility to sample of fifteen farmers, data collection took place during the month of February of the year of 2015. The results of the analysis made it possible to ensure that $100 \%$ of the farmers interviewed do not use the feature of NF-e; $53.33 \%$ do not have resources technological features to the practice of procedure; $60 \%$ revealed that they don't know the e-tool, made sure that $70 \%$ of producers responded that they would not have difficulty in the use of the process to carry out the sale of production, as well as $80 \%$ of the producers reported that information about the NF-e could be provided by financial services providers.

Keywords: NF-e. Eletronic archive. Technology.

\footnotetext{
${ }^{1}$ Bacharel em Ciências Contábeis, Universidade do Estado de Mato Grosso - UNEMAT, campus universitário de Tangará da Serra-MT. E-mail: lino.1202@hotmail.com.

2 Orientador e Professor do curso de Ciências Contábeis da Universidade do Estado de Mato Grosso UNEMAT, campus universitário de Tangará da Serra-MT. Mestre em Contabilidade pela Universidade do Vale do Rio dos Sinos - UNISINOS/RS. E-mail: marciomorais@ unemat.br.

${ }^{3}$ Mestrado em andamento em Ciências Ambientais, Universidade de Cuiabá - UNIC, campus universitário Beira Rio, Cuiabá-MT. E-mail: thyago_2fernandes@hotmail.com.

${ }^{4}$ Licenciado e bacharel em Ciências Biológicas, Universidade do Estado de Mato Grosso - UNEMAT, campus universitário de Tangará da Serra-MT. E-mail: marcosjuniorbio@gmail.com.

5 Acadêmica do curso de Agronomia, Universidade do Estado de Mato Grosso - UNEMAT, campus universitário de Tangará da Serra-MT. E-mail: thaiany_fer@hotmail.com. 


\title{
1. INTRODUÇÃO
}

Com o crescimento empresarial vertiginoso que vem ocorrendo nos últimos anos no Brasil se tornou imprescindível o desenvolvimento de novas tecnologias e ferramentas para acompanhar e auxiliar a gestão das entidades.

\begin{abstract}
Atualmente as empresas estão dependentes da tecnologia da informação devido às mudanças significativas que vêm ocorrendo nos mercados mundiais influenciados pelo processo da globalização e pela supremacia da tecnologia da informação. Tais fatores implicam numa atualização constante dos meios produtivos, seja na questão operacional, tática ou estratégica."6
\end{abstract}

"A informatização tem gerado um aumento de produtividade nos diversos setores econômicos e conquistado a sociedade pela facilidade e rapidez com que adquirimos ou geramos dados, informações, conhecimentos, saberes e destrezas."7

\begin{abstract}
Os avanços na pesquisa científica e as novas tendências de crescimento das inovações tecnológicas possibilitaram o surgimento de técnicas sustentáveis para o campo, instigado pelo desenvolvimento rural que trata a agricultura familiar como um segmento econômico e social em constante avanço e transformações; que permite que os agricultores tenham mais acessibilidade no uso e aplicação de tecnologias sociais e sustentáveis em prol do desenvolvimento. ${ }^{8}$
\end{abstract}

De fato, outra importante característica observada é a sistematização e a mobilização dos agricultores frente às discussões da iniciativa da cooperativa, tornando-os muito mais organizados e, consequentemente, fornecendo maior apoio e sustentabilidade na comercialização. "Fica evidente que o uso desta estratégia propicia unir indivíduos e tecnologias em um mesmo ambiente/espaço, resultando na elevação da importância econômica desse segmento e possibilitando o desenvolvimento rural, tanto para o município, quanto para o território."

${ }^{6}$ SILVA, L. F. R.; RODRIGUES, N. K. A.; MENDES, S. B. R.;ALVES, Thiago Barbosa. Nota Fiscal Eletrônica: análise dos impactos dessa tecnologia no resultado e na estrutura organizacional das empresas,2009.Disponível em:<http://sinescontabil.com.br/monosgrafias/trab_profissionais/nayara.pdf $>$ Acesso em 06/10/2014.

${ }^{7}$ CARDOSO, Kelly Cristina Ribeiro Marques. Contabilidade diante das modernas organizações. Feira de Santana: Sitientibus, 2002, p205-217.

8 IPEA - Instituto de Pesquisa Econômica Aplicada. BRASIL EM DESENVOLVIMENTO: Estado, Planejamento e Políticas Público, 2010. Disponível em:

<http://www.ipea.gov.br/bd/pdf/livro_BD_vo12.pdf>Acesso em 06/10/2014.

${ }^{9}$ CONTERATO, Marcelo Antônio. Mercados e Agricultura Familiar: interfaces, conexões e conflitos, 2013. Disponível em: <http://www.ufgrs.br/pgdr/livros/outras_publicacoes/ebooks/03_ebooks_PGDR.pdf>Acesso em:06/10/2014. 
Conforme publicado no Diário Oficial, no dia 21 de fevereiro de 2014, decreto $\mathrm{n}^{\circ}$ 2161/2014 do Regulamento do Imposto Sobre Circulação de Mercadorias e Prestação de Serviços (ICMS) ou o produtor rural que não esteja obrigado à inscrição no Cadastro Nacional Pessoa Jurídica (CNPJ), tem prazo até o dia 31 de dezembro de 2014 para iniciar a emissão de Nota Fiscal Eletrônica (NF-e). Documento de existência exclusivamente digital, a NF-e é emitida e armazenada eletronicamente com o intuito de documentar uma operação de circulação de mercadorias ou prestação de serviços; cuja validade jurídica é garantida por duas condições necessárias: a assinatura digital do emitente e a autorização de uso fornecida pela administração tributária do domicílio do contribuinte. ${ }^{10}$

“A mudança garante maior controle e segurança jurídica para os contribuintes, evitando que sejam autuados em outros Estados que recusam o recebimento de notas fiscais emitidas em papel."11

\footnotetext{
A NF-e pode ser utilizada em substituição aos seguintes documentos fiscais: Nota Fiscal, modelo 1 ou 1-A; Nota Fiscal de Venda a Consumidor, modelo 2; Nota Fiscal de Produtor, modelo 4, sendo esta, por enquanto, somente quando emitida pelo produtor rural PF ou PJ, inscrito no cadastro da Secretaria de Fazenda do Estado de Mato Grosso, SEFAZ/MT e no CNPJ. ${ }^{12}$
}

Neste contexto a atribuição do produtor rural é providenciar o programa emissor que possibilitará a emissão da NF-e, que pode ser um software desenvolvido exclusivamente para o contribuinte, ou servir-se gratuitamente do sistema disponibilizado pela SEFAZ/MT. "É também responsabilidade do produtor rural adquirir o certificado digital que valida a sua assinatura digital." 13

\begin{abstract}
A agropecuária foi o único setor que apresentou variação positiva entre os segmentos que compõem a formação do PIB, segundo indica os números do IBGE. Na comparação entre o primeiro trimestre de 2015 e o quarto trimestre de 2014, o PIB agropecuário garantiu crescimento de 4,7\%, contribuindo com R $\$ 79,6$ bilhões de reais no primeiro trimestre deste ano, equivalente a 5,65\% do total gerado no país, que corresponde a $\mathrm{R} \$ 1,408$ trilhão. ${ }^{14}$
\end{abstract}

\footnotetext{
${ }^{10}$ MINISTÉRIO DA FAZENDA: Portal da Nota Fiscal Eletrônica/Manual de Integração do Contribuinte Versão 4.0.1, Ano 2009. Disponível em:

<http:www.nfe.fazenda.gov.br/portal/listaconteudo.aspx?tipoconteudo=33¹5hhsyzk> Acesso em: 06/10/2014.

${ }^{11}$ SECERETARIA DE FAZENDA DO RIO GRANDE DO SUL. O Produtor Rural e a Nova Exigência de Nota Fiscal Eletrônica. Disponível em:

$<$ http://www.affectum.com.br/affectum_site/index.php?option=com_content \&view=article\&id=721:produtorrural-e-nf-eletronica\&catid=8:noticias\&itemid=30>Acesso em 06/10/2014.

${ }^{12}$ INFORMATIVO TÉCNICO: Nota Fiscal Eletrônica, Ed.07, 2014. Disponível em:

<http://sistemafamato.org.br/portal/famato/informativo_completo.php?id=228> Acesso em 06/10/2014.

13 Iden.

${ }^{14}$ CANAL DO PRODUTOR RURAL: Agricultura cresce 4,7\% no primeiro trimestre de 2015 e evita queda maior do Produto Interno Bruto (PIB). Disponível em:

$<$ http://canaldoprodutorcom.br/comunicacao/noticias/agricultura-cresce-47-no-primeiro-trimestre-de-2015-eevita-queda-maior-do-prod> Acesso em 06/10/2014.

\begin{tabular}{lr}
\hline Volume 4, Número 8 & Revista UNEMAT de Contabilidade \\
Ago./Dez. 2015 & ISSN: 2316-8072
\end{tabular}
}


Assim, diante das informações apresentadas, surge o seguinte questionamento: quais são as percepções da implantação e do emprego da NF-e pelos produtores rurais do município de Nova Olímpia-MT? Esta pesquisa tem como objetivo analisar estas percepções e, para isto, foram propostos os seguintes objetivos específicos: contextualizar a legislação vigente sobre a NF-e ao produtor rural, da mesma maneira, demonstrar a percepção dos impactos nas atividades do produtor rural com a implantação da NF-e.

Esta pesquisa se apresenta relevante para os produtores rurais, visto a defasagem do campo de informações e atualizações que os amparam. $\mathrm{O}$ estudo apresenta aos produtores a importância de se atentarem e atualizarem seus meios de informação e comunicação, no intuito de obter um resultado muito mais lucrativo diante de um mercado cada vez mais competitivo. Não há pesquisas voltadas ao tema em questão. O que existe é uma lacuna acerca da ciência dos produtores rurais e quais são seus conhecimentos sobre inovação e tecnologia num setor em constante desenvolvimento.

\title{
2 REFERENCIAL TEÓRICO
}

\subsection{Tecnologias utilizadas na Nota Fiscal Eletrônica}

De acordo com Crepaldi diz que "o momento atual caracteriza-se com uma intensidade de mudanças significativas como o desenvolvimento tecnológico, o aumento da competitividade do ambiente econômico e a globalização, colocando as empresas diante de novos desafios." $" 15$ As empresas dependem da tecnologia e dos sistemas para executar e gerir resultados que garantam sua sobrevivência no mercado, elevando seu grau de competitividade.

\begin{abstract}
A internet teve origem nos Estados Unidos nas bases militares e nos centros de pesquisas das Universidades da Califórnia, de Los Angeles, Santa Barbara, Universidade de Utah e do instituto de pesquisa de Stanford, onde foram desenvolvidas pesquisas com o propósito de solucionar os problemas enfrentados pelos militares, principalmente, para a comunicação, conexão, armazenamento e transmissão das informações de modo seguro. ${ }^{16}$
\end{abstract}

Segundo Cornachione (2001) explica que internet é como um conjunto de facilidades de comunicação e conectividade por meio de rede de computadores. Para ter acesso à rede é

15 CREPALDI, Silvio Aparecido. Contabilidade Gerencial: Teoria e Prática, p.15, 5ª ed. São Paulo: Atlas, 2011.

16 SILVA, L. F. R.; RODRIGUES, N. K. A.; MENDES, S. B. R.;ALVES, Thiago Barbosa. Nota Fiscal Eletrônica: análise dos impactos dessa tecnologia no resultado e na estrutura organizacional das empresas, 2009. Disponível em:〈http://sinescontabil.com.br/monosgrafias/trab_profissionais/nayara.pdf> Acesso em $06 / 10 / 2014$ 
necessário de um computador, de um servidor (provedor) e ter um conhecimento mínimo de informática, com esses requisitos o usuário pode conectar-se e navegar a qualquer momento e hora do dia ou da noite, pois a conexão é instantânea, as informações estão disponíveis para serem visualizadas e baixadas a qualquer momento.

\footnotetext{
Uma das ferramentas para se utilizar a internet em transações comerciais é o certificado digital, que é um documento ou uma forma de credencial eletrônica que identifica uma pessoa (física e jurídica), uma máquina ou uma entidade na internet. Este certificado possui dados pessoais do titular como o nome, o endereço, a chave pública, número de série, assinatura digital da Autoridade Certificadora, dentre outras. ${ }^{17}$
}

A Cartilha de Certificado Digital (2012) esclarece que as autoridades certificadoras possuem deveres e obrigações que são descritos em um documento chamado de Declaração de Práticas de Certificado. No Brasil, os principais tipos de certificados digitais utilizados são: A1 e A3. O primeiro tipo é aquele que é gerado e armazenado em computador pessoal, como arquivo. O segundo tipo consta como sendo o mais confiável, uma vez que oferece maior segurança em razão dos dados serem gerados, processados e armazenados em cartão modelo Smart Cards ou Tokens, correspondentes com o cartão de Cadastro de Pessoa Física (CPF).

\subsection{Nota Fiscal Eletrônica}

Em 19 de dezembro de 2003 foi promulgada a Emenda Constitucional $n^{\circ} 42$ que acrescentou o inciso XXII no artigo 37 (trinta e sete) da Constituição Federal de 1988. Esse novo inciso determinou que as quatro esferas de administração tributária da União, dos Estados, do Distrito Federal e dos Municípios agissem de forma integrada, principalmente com o compartilhamento de cadastros e de informações contábil e fiscal realizado pelos contribuintes. Com a finalidade em atender este dispositivo legal foi realizado, em Salvador, em julho de 2004, nos dias 15, 16 e 17, o primeiro Encontro Nacional de Administradores Tributários (ENAT); ocasião em que foi discutida a forma de integralização das informações entre as esferas de governo e as entidades públicas; a padronização e a uniformização destas (SILVA et al, 2009).

17 CARTILHA DO CERTIFICADO DIGITAL: Certificado Digital Ano 2012. Disponível em: $<$ http://www.sebrae.com.br/site/PortalSebrae/artigos/Certifica\%C3\%A7\%C3\%A3o-Digital-ganha-cartilha-emtr\%C3\%AAs-vers\%C3B5es>Acesso em 06/10/2014. 
O projeto NF-e tem como objetivo a implantação de um modelo nacional de documento fiscal eletrônica que venha substituir o modo atual de emissão do documento fiscal em papel, modelos 1 e 1A, com validade jurídica garantida pela assinatura digital do emitente, simplificando as obrigações acessórias dos contribuintes e permitindo, ao mesmo tempo, o acompanhamento em tempo real das operações comerciais pelo Fisco. ${ }^{18}$

Este acontecimento concebeu um cenário para celebração de vários ajustes e atos para harmonizar a legislação com o projeto da NF-e: o ajuste SINIEF 07 de 2005 e o Ato COTEPE 72 de 2005 estabeleceram definitivamente a Nota Fiscal Eletrônica. Dessa maneira, na cláusula primeira instituiu-se a Nota Fiscal Eletrônica- NF-e, que poderia ser utilizada pelos contribuintes do Imposto sobre Produtos Industrializados (IPI) ou Imposto Sobre Operações Relativas à Circulação de Mercadorias e sobre a Prestação de Serviços de Transporte Interestadual e Intermunicipal e de Comunicação (ICMS) em substituição a Nota Fiscal modelo 1 elou Nota Fiscal de Produtor, modelo 4 (AJUSTE SINIEF, 2005).

Em 19 a 21 de setembro de 2011, foi realizado em Belém, no Estado do Pará, o último encontro que teve como pauta a proposta de novos protocolos de cooperação técnica discutindo sobre os diversos temas envolvendo o Sistema Público de Escrituração digital (SPED) e possível criação ou aperfeiçoamento dos subsistemas. Instituído pelo governo através de um decreto firmado em janeiro de 2007, com o SPED, a NF-e é um documento (arquivo) que registra e armazenam dadas, informações de transações comerciais e prestações de serviços, virtualmente, com anuência da administração tributária do domicílio do contribuinte, que tem validade jurídica pela assinatura digital do empresário (SILVA et al, 2009).

A empresa emissora da NF-e gera um arquivo eletrônico com as informações fiscais da operação realizada entre o empresário e o consumidor. "Este arquivo eletrônico é a nota eletrônica que será transmitida, pela internet, para a Secretaria da Fazenda de jurisdição do contribuinte, que valida o arquivo, autorizando, em seguida, o uso do mesmo."19

“A NF-e será transmitida para a Receita Federal, que será repositório nacional de todas NF-e emitidas (ambiente nacional); no caso de operação interestadual será transmitida para a

\footnotetext{
${ }^{18}$ MINISTÉRIO DA FAZENDA: Portal da Nota Fiscal Eletrônica/Manual de Integração do Contribuinte Versão 4.0.1, Ano 2009. Disponível em:

<http:www.nfe.fazenda.gov.br/portal/listaconteudo.aspx?tipoconteudo=33¹5hhsyzk> Acesso em: 06/10/2014.

${ }^{19}$ OLIVEIRA, Luís Martins de. Manual de Contabilidade Tributária: Textos e Testes com respostas et. al 10 ed, p.281. São Paulo: Atlas 2011. 
Secretaria de Fazenda de destino da operação e Suframa na condição de mercadorias destinadas às áreas incentivadas." 20

A emissão da Nota Fiscal Eletrônica é bastante simples. O empresário primeiramente, deve adequar seus sistemas com a tecnologia utilizada pelo documento em questão e, logo após, solicitar o seu credenciamento junto a Secretaria da Fazenda (SEFAZ) do seu Estado, via internet, na página do Portal da Nota Fiscal Eletrônica. Em seguida a SEFAZ analisará o pedido observando alguns pontos essenciais como: o tipo de sistema utilizado pelo emissor; à equipe responsável pela implantação do documento na entidade; a localização do estabelecimento comercial, dentre outras, se estes itens estiverem corretamente e em conformidade com o "Manual de Integração-Contribuinte" o pedido será deferido e o solicitante estará apto a emitir a NF-e (SILVA et al, 2009).

\begin{abstract}
Em uma transação comercial a empresa gera um arquivo eletrônico que contém todas as informações fiscais e comerciais que será assinado digitalmente pelo emitente. Este arquivo será transmitido via internet, à SEFAZ para a pré-validação do arquivo que devolverá um protocolo de autorização de uso do documento para a o reenvio definitivo e consequentemente a emissão do Documento Auxiliar da Nota Fiscal Eletrônica (DANFE); sem o qual não poderá haver o transito da mercadoria. ${ }^{21}$
\end{abstract}

Logo após o recebimento pela SEFAZ do arquivo, o emitente do documento imprimirá o DANFE que acompanhará e autorizará o transito da mercadoria. É proibida a movimentação da mercadoria na ausência deste documento. Depois desta fase o comprador pode consultar a qualquer momento a NF-e para acompanhar ou simplesmente para ter controle da mercadoria adquirida. A SEFAZ estadual conjuntamente com a receita federal do Brasil, de posse das informações e da pós-validação dos dados, poderá fazer cruzamentos de dados e de informações para realizarem uma fiscalização eficiente (SILVA et al, 2009).

Conforme o Portal da Nota Fiscal Eletrônica (2012), alguns dos principais benefícios oferecidos com o uso da Nota Fiscal Eletrônica para o contribuinte vendedor são: redução de custos de impressão; redução de custos de aquisição de papel; redução de custos de envio do documento fiscal; redução de custos de armazenagem de documentos fiscais; simplificação de

20 SILVA, L. F. R.; RODRIGUES, N. K. A.; MENDES, S. B. R.;ALVES, Thiago Barbosa. Nota Fiscal Eletrônica: análise dos impactos dessa tecnologia no resultado e na estrutura organizacional das empresas,2009.Disponível em:<http://sinescontabil.com.br/monosgrafias/trab_profissionais/nayara.pdf $>$ Acesso em 06/10/2014.

${ }^{21}$ SILVA, L. F. R.; RODRIGUES, N. K. A.; MENDES, S. B. R.;ALVES, Thiago Barbosa. Nota Fiscal Eletrônica: análise dos impactos dessa tecnologia no resultado e na estrutura organizacional das empresas,2009.Disponível em:<http://sinescontabil.com.br/monosgrafias/trab_profissionais/nayara.pdf $>$ Acesso em 06/10/2014. 
obrigações acessórias, como dispensa de AIDF e redução de tempo de parada de caminhões em postos fiscais de fronteira (B2B) (SECRETARIA DE FAZENDA DO ESTADO DE SÃO PAULO, 2012).

Sendo um documento exclusivamente eletrônico a possibilidade de erro de digitação é mínima, visto que, antes de ser emitido o arquivo é analisado pela SEFAZ, impossibilitando, desta forma, erro na emissão do documento e consequentemente na escrituração. Há também, redução de tempo para o empresário se dedicar a outra atividade que tenha prioridade. $\mathrm{O}$ Portal da Nota Fiscal Eletrônica (2012) aponta os principais benefícios para a administração tributária com a prática da NF-e: aumento na confiabilidade da nota fiscal; melhoria no processo de controle fiscal, possibilitando um melhor intercâmbio e compartilhamento de informações entre os Fiscos; redução de custos no processo de controle das notas físcais capturadas pela fiscalização de mercadoria em trânsito; suporte aos projetos de escrituração eletrônica contábil e fiscal da Secretaria da RFB (Sistema de Escrituração Digital-SPED) e a diminuição da sonegação e aumento de arrecadação (PORTAL DA NOTA FISCAL ELETRÔNICA, 2012).

O mais interessado na implantação do projeto de SPED conjuntamente com a Nota Fiscal Eletrônica é o Fisco, porque obriga os contribuintes a prestar informações claras e corretas, diminuindo as possíveis ilicitudes e sonegação fiscal contra o ente público. Também facilita maior fiscalização, pois o Fisco sabe a quantidade da transação realizada pelo contribuinte quase que em tempo real, antes mesmo de ocorrer o fato gerador. Com posse dos dados comerciais das empresas o Fisco realizará a fiscalização através de compartilhamento e cruzamentos das informações entre as esferas de governo e das entidades públicas fiscalizadoras, diminuindo o tempo desta operação e a consequente realização de uma fiscalização eficiente (SILVA et al, 2009).

\subsection{Produtor Rural}

Conforme a legislação do imposto de renda nos artigos 58 a 71 do RIR/99, o produtor rural é a pessoa física ou natural que explora atividades agrícolas e pecuárias, como: a extração e a exploração vegetal e animal; exploração de apicultura; avicultura; suinocultura; sericultura; piscicultura e outras criações de pequenos animais. Também estão inseridos nesse contexto os produtos agrícolas ou pecuários que são transformados sem ocorrer alterações na composição. "A legislação do imposto de renda sobre pessoa física ressalta ainda que as 
atividades exercidas pelo produtor rural devem ser executadas pelo próprio agricultor ou criador, com o auxílio de máquinas e equipamentos exclusivos da atividade rural."22

"Batalha et. al. salientam que "o tripé fundamental para a competitividade sustentada" é formado pela pesquisa dos processos de produção, pesquisa para o desenvolvimento de novos produtos e pela pesquisa no campo da tecnologia de gestão." ${ }^{23}$ Partindo da premissa mencionada por Batalha et. al. (2004), de que todas as tecnologias e conhecimentos são relevantes para garantir que pequenas propriedades possam ter condições de competir nos mercados em que atuam, "visualizamos a necessidade de investigar acerca da eficácia do emprego de tecnologias nas pequenas unidades rurais." 24

O meio rural sofreu, especialmente nas últimas três décadas, profundas alterações na sua configuração. "Os produtores tiveram de se adaptar a mudanças nas formas de produção, de comercialização e, até mesmo, de relações sociais, que implicaram na necessidade de aderir a inovações tecnológicas, rever a gestão das propriedades e se adequar a visão empresarial de administração do negócio agrícola. “25

De acordo com Sorj (2003) conceitua que a exclusão digital depende de cinco fatores que determinam em maior ou menor universalização dos sistemas telemáticos. São eles:

1- A existência de infraestruturas físicas de transmissão;

2- A disponibilidade de equipamentos/conexão de acesso (computador, modem, linha de acesso);

3- Treinamento no uso de instrumentos do computador e da internet;

4- Capacitação intelectual e inserção social do usuário, produto da profissão, do nível educacional e intelectual e de sua rede social, que determinam o aproveitamento efetivo da informação e das necessidades de comunicação pela internet;

5- A produção e o uso de conteúdos específicos adequados às necessidades dos diversos segmentos da população. ${ }^{26}$

\footnotetext{
22 TAtiARA, Wégela Maia Passos. Produtor Rural: Um Estudo Comparativo entre Pessoa Física e Pessoa Jurídica Agroindustrial, 2013. Disponível em:

<http://semanaacademica.org.br/system/artigos/artigocientificoprodutorrural.pdf>Acesso em 06/10/2014.

${ }^{23}$ BATALHA, Mario Otávio et al. Tecnologia de Gestão e Agricultura Familiar. In: XLII Congresso da Sociedade Brasileira de Economia e Sociologia Rural, 2004, Cuiabá-MT.

${ }^{24}$ CEZAR, Leandro Neukirchen; ZANCHET, Aládio; PAULA, Germano de. Desenvolvimento De Pequenas Propriedades Rurais e a Utilização De Tecnologias. Disponível em:

<http://www.unioeste.br/campi/cascavel/ccsa/IVSeminario/IVSeminario/Artigos/05.pdf> Acesso em 06/10/2014

${ }^{25}$ CRESTANI, Verônica Viero; CRISTINA, Ada Machado da Silveira. Apropriação De Tecnologias De Informação E Comunicação No Meio Rural Brasileiro, 2011. Disponível em:<https://www.marilia.unesp.br/Home/Graduacao/PETBiblioteconomia/apropriacao-de-tic-no-meio-ruralbrasileiro.pdf> Acesso em 06/10/2014.

${ }^{26}$ SORJ, B. Brasil do povo: a luta contra a desigualdade na sociedade da informação. Rio de Janeiro: Jorge Zahar, 2003. 
Os primeiros dois critérios se referem a dimensões passivas do acesso à internet, à medida que os três últimos definem o potencial de apropriação ativa (SORJ, 2003). O aspecto infraestrutura é um dos maiores entraves à universalização do acesso à internet, ainda representa um problema nas pequenas vilas e zonas rurais. "A conexão banda larga praticamente só é acessível nos centros urbanos. Outro problema relacionado à inclusão digital no meio rural se refere à ausência de conteúdos específicos para essas comunidades.”27

Segundo Mañas (2002), para produzir informações e conhecimento na propriedade rural é preciso habilitar, preparar o produtor agrícola que conduzirá o processo das informações e o gerenciamento da propriedade, o que é primordial para a correta tomada de decisão, que depende principalmente das fontes (origens) utilizadas e de como as informações fluem dentro e fora da propriedade agrícola.

A adaptação das propriedades rurais ao mercado consumidor é de fundamental importância para alcançar os resultados. São várias as formas de atingi-los, entre elas, a escolha das melhores culturas, a diversificação agrícola e a utilização de sistemas produtivos, dado que as inovações têm como objetivo maior as tornarem competitivas para alcançarem os resultados em curto espaço de tempo. "Apodera-se como fatores da propriedade rural ideal: o retorno financeiro em curto prazo e a sobrevivência em longo prazo; segmentos determinados; saber como proceder no mercado e está preparado para se adequar à mudança de ambiente e de aprendizagem para atingir o objetivo desejado." 28

\section{METODOLOGIA}

O método que nos reportamos para este estudo é o método descritivo, de natureza quantitativa, que, segundo Gil (2002), é a forma de pesquisa que tem como principal característica descrever as particularidades de uma determinada população. Procuramos analisar a percepção do produtor rural com o uso da NF-e, assim como procuramos analisar quais suas percepções em relação ao uso dessas informações.

\footnotetext{
27 CRESTANI, Verônica Viero; CRISTINA, Ada Machado da Silveira. Apropriação De Tecnologias De Informação E Comunicação No Meio Rural Brasileiro, 2011. Disponível em:<https://www.marilia.unesp.br/Home/Graduacao/PETBiblioteconomia/apropriacao-de-tic-no-meio-ruralbrasileiro.pdf> Acesso em 06/10/2014.

28 MAÑAS, A. V. Administração De Sistemas E Informações. São Paulo: Editora Érica, 2002. MINISTERIO DA FAZENDA. Portal Da Nota Fiscal Eletrônica. Disponível em: <http://www.nfe.fazenda.gov.br/portal/principal.aspx> Acesso em 06/10/2014. 
Nesse tipo de pesquisa, os fatos são observados, registrados, analisados, classificados e interpretados, sem que o pesquisador interfira neles. Isto significa que os fenômenos do mundo físico e humano são estudados, mas não manipulados pelo pesquisador. ${ }^{29}$

Houve então a necessidade de quantificar as informações coletadas. Richardson (1999), diz que os métodos quantitativos se caracterizam pelo emprego da quantificação tanto nas modalidades de coleta de informações, quanto no tratamento delas por meios estatísticos, desde os mais simples aos mais complexos. O questionário aplicado aos entrevistados foi fundamentado pelo referencial teórico selecionado e ocupa a condição de importante instrumento de coleta para esta pesquisa. "Segundo Vergara, a pesquisa bibliográfica é "o estudo sistematizado desenvolvido com base em material publicado em livros, revistas, jornais, redes eletrônicas, isto é, material acessível ao público em geral."30 "Oliveira menciona que a pesquisa bibliográfica tem por finalidade conhecer as diferentes formas de contribuição científica que se realizaram sobre determinado assunto ou fenômeno."31

Para a coleta e obtenção dos elementos foi realizado um levantamento ou survey ${ }^{32}$ que, conforme Colauto e Beuren (2006) são dados coletados nesse tipo de pesquisa, e que podem ser baseados numa amostra retirada da população, mas sempre levando em consideração que nenhuma amostra é perfeita, podendo variar o grau de erro ou viés. Gil (2002, p.70), conceitua a pesquisa de levantamento ou survey, da seguinte maneira:

"[...] se caracterizam pela interrogação direta das pessoas cujo comportamento se deseja conhecer. Basicamente, procede-se a solicitação de informações a um grupo significativo de pessoas acerca do problema estudado para em seguida, mediante análise quantitativa, obter as conclusões correspondentes aos dados coletados." 33

Para a realização da pesquisa os dados foram levantados por meio de questionários, utilizando o método por acessibilidade, onde os participantes foram selecionados pela facilidade de acesso, ao invés do método de amostragem não probabilística. "Gil argumenta

${ }^{29}$ ANDRADE, Maria Margarida. Introdução à metodologia do trabalho científico. P.124.7. ed. São Paulo: Atlas, 2005.

${ }^{30}$ VERGARA, Sylvia C. Projetos e relatórios de pesquisa em administração. São Paulo: Atlas, 2006.

${ }^{31}$ OLIVEIRA, Silvio Luiz de. Tratado de metodologia científica. 2.ed. São Paulo: Pioneira, 1999.

32 Survey é um método de coleta de informações diretamente de pessoas a respeito de suas ideias, sentimentos, saúde, planos, crenças e de fundo social, educacional e financeiro. Disponível em:http://www.carlosmello.unifei.edu.br/Disciplinas/Mestrado/PCM-10/Gráficos

Mestrado/Metodologia_Pesquisa_2012-Gráfico_Aula_9_Mestrado.pdf

${ }^{33}$ GIL, Antônio Carlos. Como elaborar projetos de pesquisa. P.70.4. ed. São Paulo: Atlas, 2002. 
que esse tipo de amostragem não representa fundamentação matemática ou estatística, dependendo única e exclusivamente do pesquisador. $O$ autor ainda conceitua que o pesquisador seleciona os elementos a que tem acesso, considerando que de alguma forma eles representam aquele universo." 34

A população pesquisada foi de 35 produtores rurais, que foram apresentados pelas empresas de serviços contábeis do município de Nova Olímpia, Estado de Mato Grosso, que prestam serviços contábeis a esses produtores com situação ativa no cadastro da SEFAZ-MT. A amostra de 15 respondentes foi selecionada pela acessibilidade aos mesmos. A coleta dos dados ocorreu no mês de fevereiro de 2015 com a aplicação do questionário composto por 13 perguntas fechadas.

As informações obtidas foram armazenadas em um banco de dados para posteriormente serem quantificadas e submetidas à análise. O tratamento dos dados foi realizado por meio da utilização do programa Microsoft Excel 2013®, através da construção de quadros de frequência simples e gráficos que, "para Sampieri é um conjunto de pontuações ordenadas em suas respectivas categorias." 35

\section{RESULTADOS E DISCUSSÃO}

Os resultados finais foram obtidos após os dados serem tabulados, quantificados e analisados. Notou-se que $100 \%$ dos produtores rurais fazem a utilização de emissão de nota fiscal modelo bloco de notas e possuem conhecimento acerca da emissão de NF-e.

Diante da necessidade de emissão de documento fiscal na venda de suas produções conforme gráfico $01,13,33 \%$ dos produtores responderam que emitem nota fiscal há um ano; $20 \%$ deles emitem entre um a cinco anos; $46,67 \%$ confirmaram que já emitem nota fiscal de venda de suas produções em média de cinco a dez anos. Estes resultados demonstram a preocupação dos produtores rurais em emitir a nota fiscal de venda para a comercialização de sua produção.

\footnotetext{
${ }^{34}$ GIL, Antônio Carlos. Métodos e técnicas de pesquisa social. 6. ed. São Paulo: Atlas, 2011.

35 SAMPIERI, R. H. Metodologia de pesquisa. Tradução de Fatima Conceição Murad, Melissa Kassner, Sheila Cara Dystyler Cadeira. 3.ed. São Paulo: Mcgraw-Hill. 2006. 416p.
} 
Gráfico 01- Há quanto tempo você faz utilização da emissão da nota fiscal pela comercialização dos seus produtos?

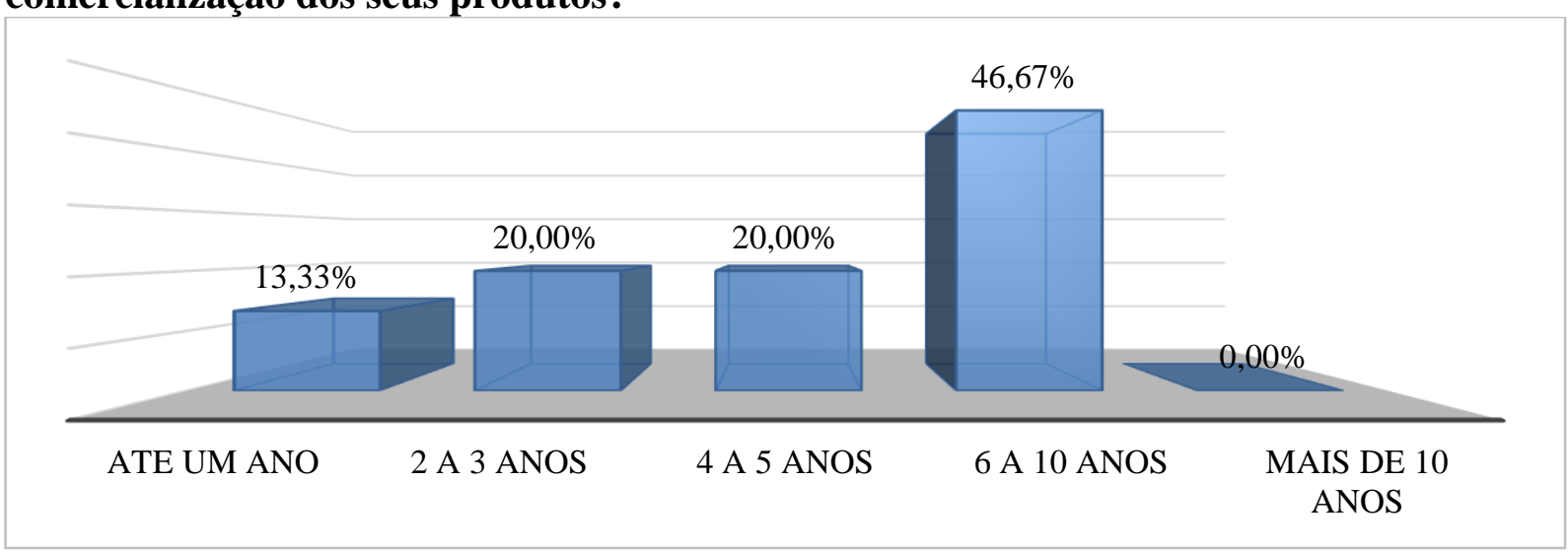

Fonte: Dados da pesquisa.

No gráfico 02 percebe-se que 53\% dos produtores recorrem ao seu prestador de serviços fiscais (contador), para a emissão das notas fiscais de venda de sua produção. E que revela uma situação preocupante, pois a responsabilidade de emissão de notas fiscais de venda é do próprio produtor rural, conforme Art.178 (Portal da SEFAZ/MT,2014) “Os contribuintes, excetuados os produtores não equiparados a estabelecimento comercial ou industrial, emitirão Nota Fiscal: (cf. inciso VIII do art. 17 da Lei $n^{\circ}$ 7.098/98 c/c o art. 18 do Convênio SINIEF $s / n^{\circ}$ e respectivas alterações) ", $34 \%$ utilizam o próprio escritório na fazenda ou o escritório da fazenda na cidade e, apenas $13 \%$ utilizam outros, ou seja, se dirigem até a cidade para emissão da nota fiscal avulsa 1B.

\section{Gráfico 02- As notas fiscais de venda de sua produção são emitidas}

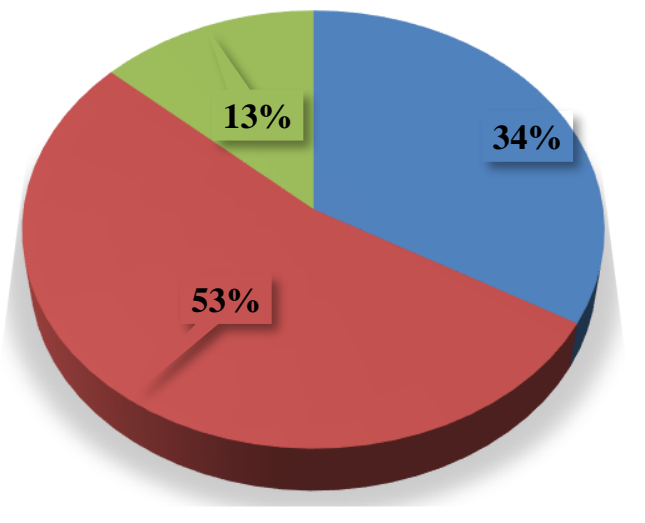

- Propriedade rural ou escritório da propriedade rural na cidade

- Prestador de serviços fiscais

- Outros

Fonte: Dados da pesquisa. 
Quanto à segurança dos dados emitidos e recebidos pelos produtores rurais do município supracitado, o Gráfico 03 nos mostra que, $73 \%$ deles responderam não manter as notas fiscais de comercialização de suas mercadorias juntamente ao seu prestador de serviço, enquanto $27 \%$ responderam manter esta ligação.

Gráfico 03: Você mantém suas notas fiscais de comercialização de suas mercadorias junto a seu prestador de serviço fiscal?

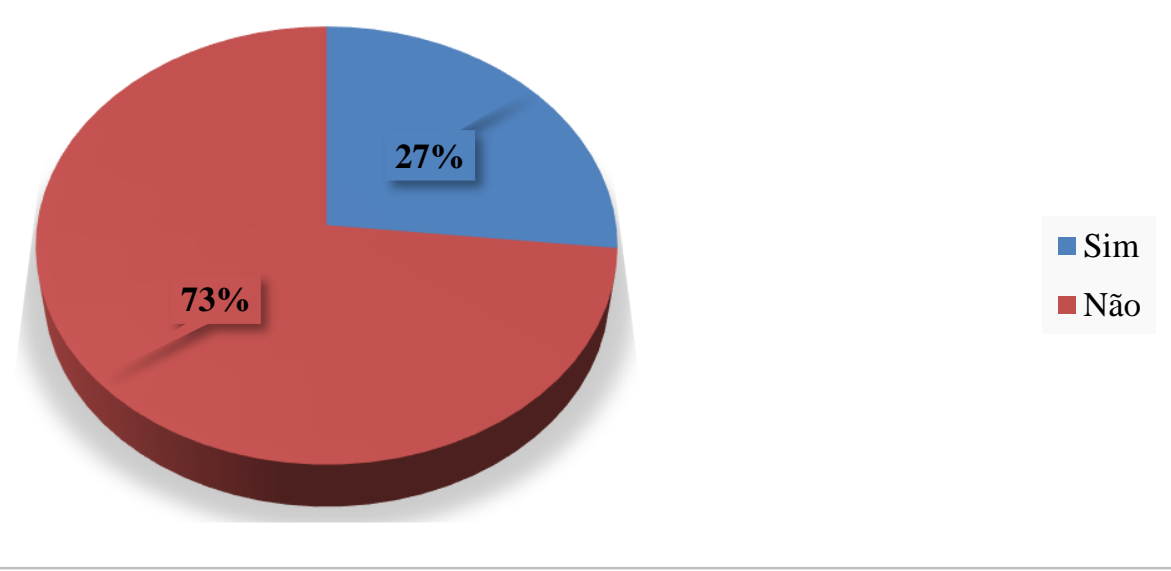

Fonte: Dados da pesquisa.

O gráfico 04 a seguir mostra a necessidade de recursos tecnológicos para emissão da NFe, apenas $46,67 \%$ dos produtores rurais responderam possuir computadores; $26,67 \%$ possuem computador e impressora; 46,67\% têm acesso a internet na propriedade rural e 53,33\% não possuem, uns alegaram motivos particulares para a aquisição dos equipamentos eletrônicos, outros pela dificuldade de acesso à internet, existe propriedade em região de difícil acesso até mesmo para conexão via rádio.

Gráfico 04: Quais recursos tecnológicos sua propriedade rural ou escritório de sua fazenda na cidade tem à disposição 


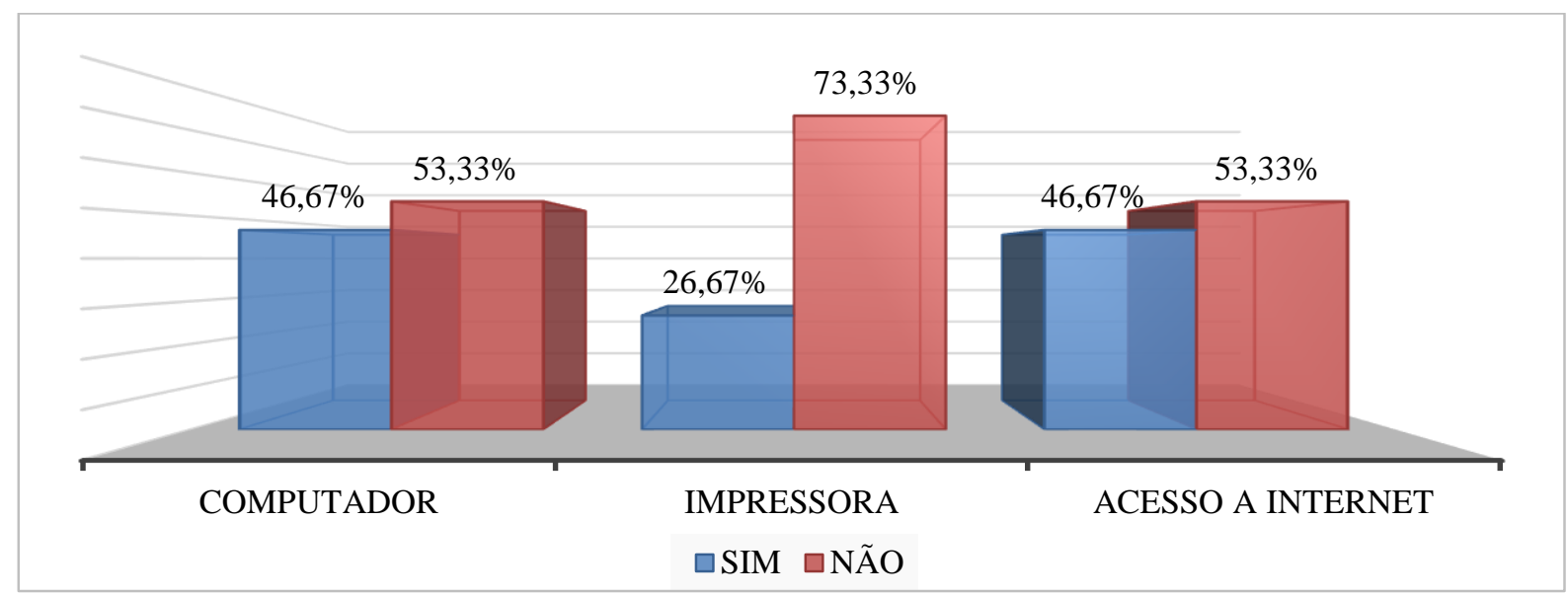

Fonte: Dados da pesquisa.

Conforme gráfico 05 abaixo, $60 \%$ dos produtores assumiram conhecer o documento fiscal eletrônico; $40 \%$ desconhecem esse procedimento fiscal. Os dados também revelam que a maioria dos produtores conhece o que é a NF-e, mesmo que apenas por compras de mercadorias.

Gráfico 05: Você sabe o que é uma Nota Fiscal Eletrônica (NF-e)?

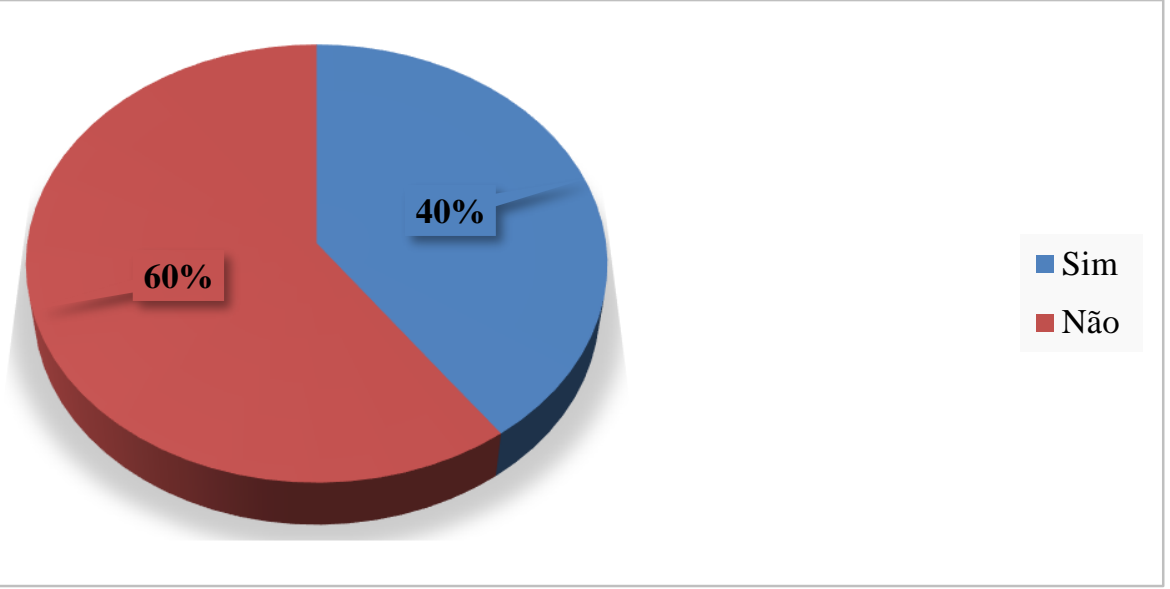

Fonte: Dados da pesquisa.

Conforme demonstra o gráfico 06, quanto ao conhecimento na mudança do modelo da nota fiscal modelo 1A para NF-e, $80 \%$ dos produtores alegaram desconhecer as mudanças, provavelmente em virtude da falta de comunicação entre produtores rurais, prestadores de serviços contábeis e Governo. Apenas 20\% reconhecem as mudanças propostas pelo Governo.

Gráfico 06: Você tem conhecimento sobre a mudança no modelo da nota fiscal (modelo impresso para NF-e) utilizada na venda da produção rural a partir do ano de 2015 ? 


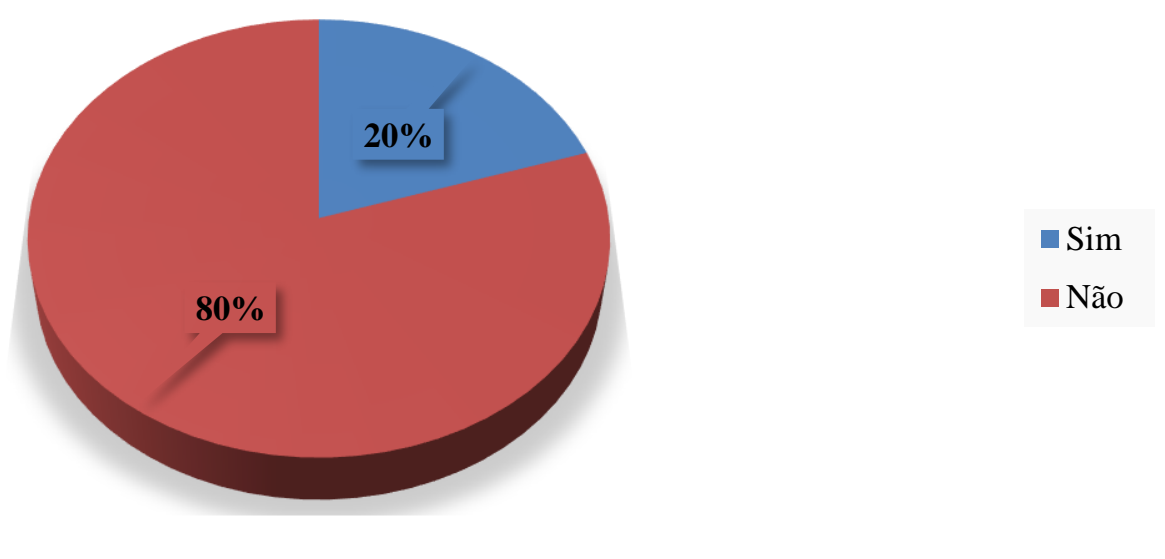

Fonte: Dados da pesquisa.

Dos que afirmaram reconhecer o procedimento da mudança do modelo da nota fiscal, o gráfico 07 demonstra que, 67\% foram favoráveis à alteração, pois sabem da facilidade da emissão e do manuseio da NF-e, enquanto 33\% não souberam responder, mesmo conhecendo o procedimento da NF-e, adquirida através da compra dos insumos e matéria prima para a sua produção.

\section{Gráfico 07: Se sim, qual sua opinião sobre isso?}

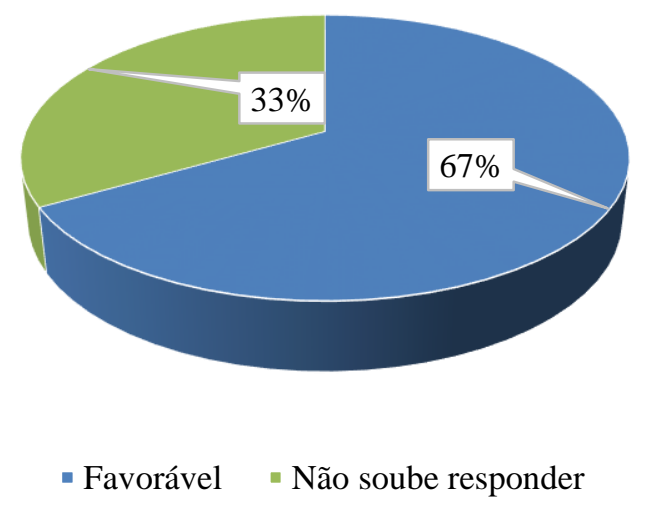

Fonte: Dados da pesquisa.

No gráfico 08 diante da atividade comercial no momento da emissão da NF de vendas de produtos, $73 \%$ dos produtores rurais responderam que não encontrariam dificuldades na utilização da NF-e para suas vendas; $27 \%$ disseram que sim, que teriam dificuldades para a prática.

Gráfico 08: Você acredita que encontrará dificuldade(s) na utilização da NF-e para realizar a venda de sua produção? 


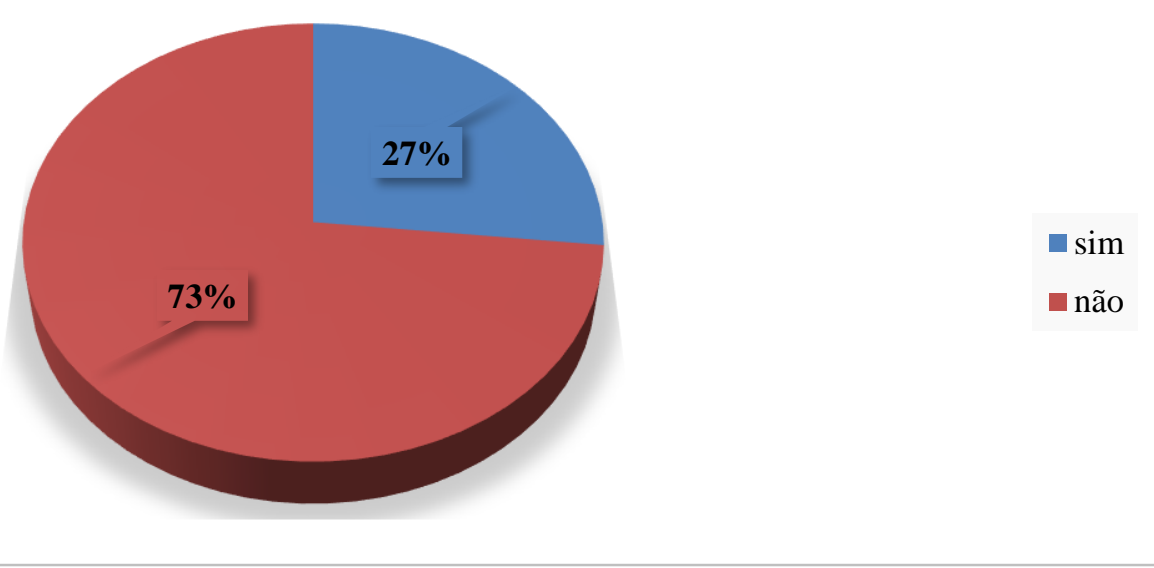

Fonte: Dados da pesquisa.

Na sequência, conforme quadro 01, demonstrou-se o nível de dificuldade para emissão da NF-e por parte dos produtores rurais; $53 \%$ dos produtores alegaram, para a alternativa importação para o sistema contábil, que teriam muita dificuldade na emissão da NF-e, pois precisariam aprender sobre o sistema e cadastro de produtos e clientes; $27 \%$ deles acreditam que seria difícil, e $20 \%$ disseram que não seria difícil e nem que seria fácil.

No quesito dificuldade para a utilização do programa emissor da NF-e, $40 \%$ dos produtores responderam que encontrariam dificuldades no uso do sistema; ressaltaram também os custos que teriam que ser aplicados na implantação do sistema, na compra dos equipamentos de informática e internet, e no treinamento pessoal para o setor de faturamento fiscal; $60 \%$ disseram que a prática facilitaria o processo em razão da rapidez da emissão fiscal e da comunicação direta com o Fisco.

Diante da necessidade do manuseio ou operacionalidade para emissão da NF-e, $60 \%$ alegaram que não haveria dificuldade, mas que também não seria de fácil utilização; $40 \%$ responderam que a prática simplificaria e facilitaria o procedimento fiscal.

Quanto à questão de informação acerca da NF-e, $80 \%$ dos produtores afirmaram que não encontrariam dificuldades para obterem as informações que deveriam ser comunicadas pelos seus prestadores de serviços fiscais; apenas $7 \%$ responderam que a prática não facilitaria ou dificultaria o processo; $13 \%$ reconheceram a facilidade que a prática proporcionaria para o procedimento que seria devidamente acompanhado pela empresa de serviços contábeis.

Para o quesito disponibilidade de internet na fazenda, um total de $40 \%$ alegaram que encontrariam grandes dificuldades em razão da localização de suas propriedades.

A longitude entre propriedades e município dificultaria o acesso até mesmo à internet via rádio; $33 \%$ encontrariam dificuldades em virtude do alto custo para a implantação da internet; apenas $27 \%$ responderam que não encontrariam dificuldades ou facilidades para o 
estabelecimento da conexão, mas afirmaram que não haveria necessidade de implantação de internet.

Quadro 01: Qual procedimento para emissão de NF-e teve ou teria dificuldade(s), enumerado de 1 a 5 , sendo 1 para mais difícil e 5 menos difícil.

\begin{tabular}{|l|c|c|c|c|c|c|}
\hline \multirow{2}{*}{\multicolumn{1}{|c|}{ DIFICULDADES }} & \multicolumn{7}{c|}{ NIVEL DE DIFICULDADE } \\
\cline { 2 - 8 } & $\begin{array}{c}\text { Muito } \\
\text { Difícil }\end{array}$ & Difícil & $\begin{array}{c}\text { Nem } \\
\text { Difícil } \\
\text { Nem Fácil }\end{array}$ & Fácil & $\begin{array}{c}\text { Muito } \\
\text { Fácil }\end{array}$ & \\
Total \\
\hline Importação Para Sistema Contábil & $53 \%$ & $27 \%$ & $20 \%$ & $0 \%$ & $0 \%$ & $100 \%$ \\
\hline Programa Para Emissão de NF-e & $0 \%$ & $40 \%$ & $0 \%$ & $0 \%$ & $60 \%$ & $100 \%$ \\
\hline Manuseio ou Operacionalização Para Emissão da NF-e & $0 \%$ & $0 \%$ & $60 \%$ & $0 \%$ & $40 \%$ & $100 \%$ \\
\hline Informação Sobre a NF-e & $0 \%$ & $0 \%$ & $7 \%$ & $80 \%$ & $13 \%$ & $100 \%$ \\
\hline Disponibilidade de Internet & $40 \%$ & $33 \%$ & $27 \%$ & $0 \%$ & $0 \%$ & $100 \%$ \\
\hline
\end{tabular}

Fonte: Dados da pesquisa.

Conforme demonstra o gráfico $09,67 \%$ dos produtores rurais disseram desconhecer a assinatura digital, índice relativamente preocupante levando em consideração o mundo cada vez mais tecnológico e interligado por meio de processo e conexões digitais e eletrônicas. Constam dessa porcentagem os produtores cujos documentos fiscais são emitidos pelos escritórios de contabilidade contratados; 33\% dos entrevistados responderam que os documentos fiscais são emitidos pelo escritório de sua propriedade, e reconheceram a necessidade que há em acompanhar todo o método ante o Fisco.

\section{Gráfico 09: Você sabe o que é Assinatura Digital ou Certificado Digital?}




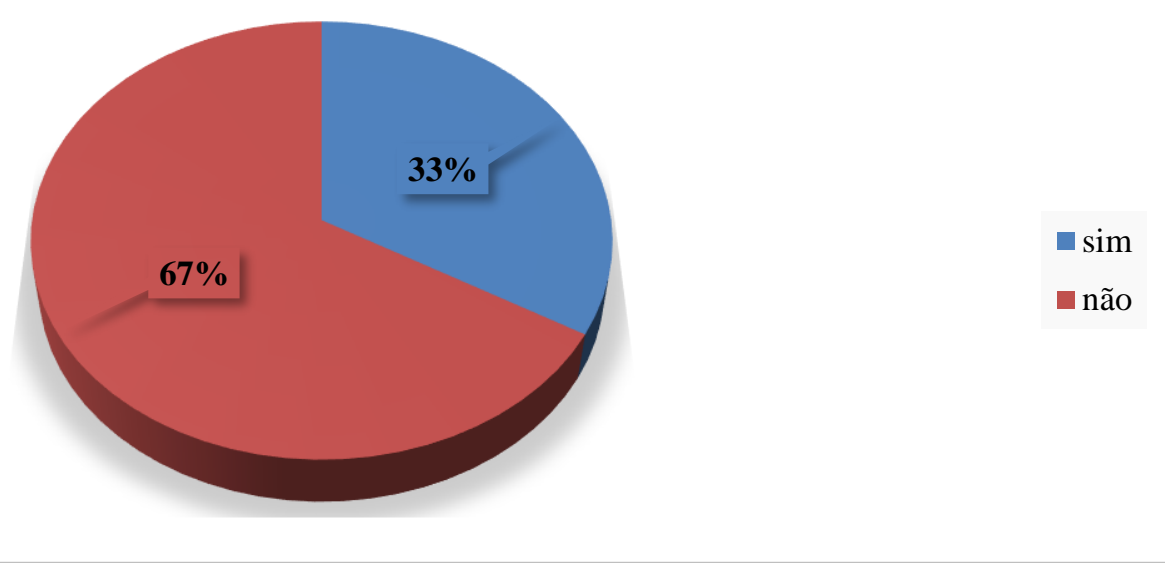

Fonte: Dados da pesquisa.

No gráfico 10 verificou-se a eventual facilidade das vendas de seus produtos por meio da emissão da NF-e, $40 \%$ dos produtores rurais reconheceram que o procedimento garantiria eficiência no controle de estoque, do mesmo modo que proporcionaria agilidade à comercialização de sua produção. Entretanto, $60 \%$ responderam que o método não provocaria nenhum tipo de impacto no seu desempenho de vendas.

Gráfico 10: Você acredita que com a utilização da NF-e, facilitará no desempenho no processo de comercialização dos seus produtos?

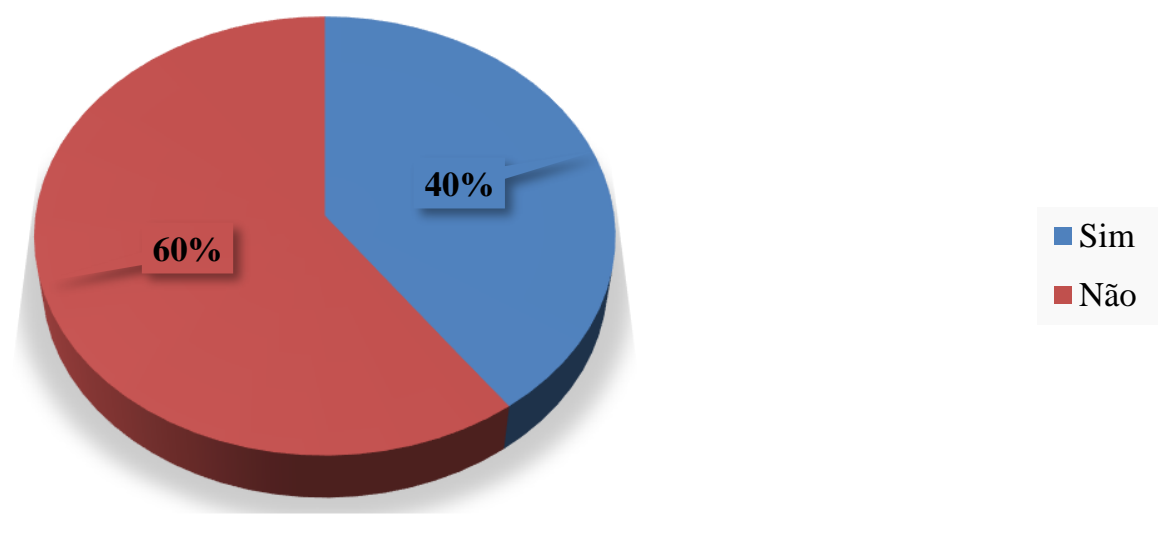

Fonte: Dados da pesquisa.

O quadro 02 apresentou-se o nível de importância das questões relacionadas a adoção da NF-e, assim como, suas consequentes melhorias para o ramo de negócio. Ainda que saibam que a adoção do método facilitaria na comunicação, a indiferença quanto à rapidez nas informações favorecida através da prática da NF-e representa $47 \%$ dos produtores rurais. Como há a necessidade do cadastro dos produtos para a emissão do documento fiscal, $60 \%$ responderam que a adoção do método contribui no controle de estoque, assim como também 
contribui para a administração das notas de entrada e despesas, oportunizando gesta o total sobre créditos e débitos.

Cerca de $20 \%$ a $27 \%$ dos produtores admitiram redução de custo decorrente da implantação da NF-e; enquanto13\% desconhecem dos benefícios derivados pela utilização do método. Para estes a redução de custos não impacta na produção ou comercialização dos produtos. O nível de importante, pouco importante, ou indiferente ao processo, representa $20 \%$ cada dos produtores entrevistados.

Quadro 02 - Situação de Adoção da NF-e e Melhorias no Ramo de Negócio

\begin{tabular}{|l|c|c|c|c|c|c|}
\hline \multicolumn{1}{|c|}{ SITUAÇÃO } & \multicolumn{7}{c|}{ NIVEL DE IMPORTÃNCIA } \\
\hline & $\begin{array}{c}\text { Muito } \\
\text { Importante }\end{array}$ & Importante & $\begin{array}{c}\text { Pouco } \\
\text { Importante }\end{array}$ & Indiferente & $\begin{array}{c}\text { Menos } \\
\text { Importante }\end{array}$ & Total \\
\hline Rapidez nas informações & $33 \%$ & $20 \%$ & $0 \%$ & $47 \%$ & $0 \%$ & $100 \%$ \\
\hline Controle de estoque & $20 \%$ & $60 \%$ & $20 \%$ & $0 \%$ & $0 \%$ & $100 \%$ \\
\hline Redução de custos & $27 \%$ & $20 \%$ & $20 \%$ & $20 \%$ & $13 \%$ & $100 \%$ \\
\hline $\begin{array}{l}\text { Estimulo aos relacionamentos } \\
\text { eletrônicos com cliente }\end{array}$ & $0 \%$ & $0 \%$ & $0 \%$ & $13 \%$ & $87 \%$ & $100 \%$ \\
\hline Alcance de novos clientes & $20 \%$ & $0 \%$ & $60 \%$ & $20 \%$ & $0 \%$ & $100 \%$ \\
\hline
\end{tabular}

Fonte: Dados da pesquisa.

No quesito estímulo de relacionamento eletrônico com os clientes, $87 \%$ dos produtores consideraram como um aspecto menos importante nesta relação; 13\% alegaram indiferença. Para eles tanto faz se o cliente tem conhecimento ou não sobre a inclusão eletrônica. Para o alcance de novos clientes, $60 \%$ consideraram importante o exercício do método, mesmo tendo a ciência de que seus principais clientes são os mercados do próprio município e outros produtores locais; $20 \%$ consideraram muito importantes a utilização do recurso, pois reconhecem que a implantação da NF-e possibilitaria novos canais de vendas, como via telefone e e-mail, resultando em comodidade a seus clientes e agindo diretamente na redução de custos; $20 \%$ se consideraram indiferentes à questão.

Com o crescimento de $4,7 \%$ no primeiro trimestre de 2015 , o setor agrícola impediu que o Produto Interno Bruto (PIB) do país apresentasse um desempenho ainda pior do que a queda de 0,2\%, conforme divulgou nesta sexta-feira, dia 29, o Instituto Brasileiro de Geografia e Estatística (IBGE). Para o presidente da Confederação da Agricultura e Pecuária do Brasil (CNA), João Martins, é em função desse desempenho que o "agronegócio precisa continuar recebendo crédito e financiamento adequados capazes de garantir mais produção e produtividade, além de manter a contribuição decisiva do agronegócio na manutenção do superávit da balança comercial brasileira". 


\section{CONSIDERAÇÕES FINAIS}

O setor tecnológico está em constante desenvolvimento e crescimento e esta nova realidade necessita de mudanças e adequações tanto na infraestrutura quanto na execução, sejam eles no âmbito político, econômico e financeiro. A mudança atrai modificações significativas para todas as partes envolvidas em uma operação comercial e também para a sociedade como um todo. Com a informatização do processo, o Fisco obtém as informações em tempo real, possibilitando uma fiscalização eficaz e eficiente e, consequentemente, o aumento na arrecadação de impostos.

Os produtores rurais do município de Nova Olímpia, Estado de Mato Grosso, conforme demonstra o gráfico 06 , tem a necessidade de se adaptarem as novas tecnologias e mudanças no setor rural e, $80 \%$ dos produtores não possuem conhecimento acerca da mudança no processo de emissão da nota fiscal de venda para Nota Fiscal Eletrônica.

Demonstrou-se que os produtores do município terão um grande impacto para a implantação da NF-e na venda de seus produtos, conforme exemplifica o gráfico 08 , em que $73 \%$ dos produtores responderam que terão ou encontrarão dificuldades na utilização do método. Há vários motivos que contribuem dificultando a prática do procedimento, entre eles o pouco conhecimento sobre as atualizações do sistema, também como pela dificuldade de acessibilidade que as empresas de comunicação possuem para chegar até as propriedades rurais. Para os produtores sua maior dificuldade será a importação das informações para o sistema contábil, conforme mostra o quadro 01 , em que $53 \%$ deles responderam que haveria muita dificuldade com a mudança.

Através da questão problema, cujo foco era analisar as percepções dos produtores rurais do município de Nova Olímpia, Estado de Mato Grosso, ante a necessidade da implantação e da prática da NF-e, pode-se perceber a dificuldade que os produtores rurais têm de estarem atualizados para as mudanças tecnológicas. É fundamental que se conheça todo o processo de emissão da NF-e, assim como também é necessário à aquisição dos equipamentos eletrônicos que possibilitem a execução do procedimento, conforme explicitado no gráfico 04 .

Portanto a percepção dos produtores rurais do município pesquisado, em razão da implantação da NF-e, é favorável a implantação, pois os mesmos possuem um conhecimento razoável no que se diz respeito a utilização da NF-e mesmo ele que terá um gasto/custo para a 
aquisição dos equipamentos e manutenção do escritório na fazenda e com pessoal adequado para a emissão da NF-e. Também, esta percepção serviria para o próprio produtor, tendo em vista suas vendas para o comercio local, onde a maioria das empresas são familiares, estarão viabilizando uma facilidade de acesso aos produtos e agilizando assim suas vendas, em função de que os mesmos poderão ser feitas por telefone ou e-mail, agregando valor e uma nova percepção sobre vendas e lucratividade nos negócios, por meio digital.

Para efeito de estudos futuros, sugere-se uma pesquisa com os produtores que já tenham implantado a NF-e, com a intenção de se comparar a situação das rotinas antes e depois da NF-e, com eventuais melhorias, dificuldades encontradas e eventual influência nos resultados, em função da nova norma fiscal.

\section{REFERÊNCIAS}

ANDRADE, Maria Margarida. Introdução à metodologia do trabalho científico. 7 . ed. São Paulo: Atlas, 2005.

AJUSTE SINIEF 07/05. Institui a Nota Fiscal Eletrônica e o Documento Auxiliar da Nota Fiscal Eletrônica Ano 2005.

Disponível em: <http://www.fazenda.gov.br/confaz/confaz/ajustes/2005/AJ_007_05.htm>. Acesso em 06/10/2014.

BATALHA, Mario Otávio et al. Tecnologia de Gestão e Agricultura Familiar. In: XLII Congresso da Sociedade Brasileira de Economia e Sociologia Rural, 2004, Cuiabá - MT.

CANAL DO PRODUTOR RURAL: Agricultura cresce 4,7\% no primeiro trimestre de 2015 e evita queda maior do Produto Interno Bruto (PIB). Disponível em: <http://www.canaldoprodutor.com.br/comunicacao/noticias/agricultura-cresce-47-noprimeiro-trimestre-de-2015-e-evita-queda-maior-do-prod> Acesso em 29/05/2015.

CARDOSO, Kelly Cristina Ribeiro Marques. Contabilidade diante das modernas organizações. Feira de Santana: Sitientibus, 2002, p.205-217.

CARTILHA CERTIFICADO DIGITAL: Certificado Digital Ano 2012. Disponível em: $<$ http://www.sebrae.com.br/sites/PortalSebrae/artigos/Certifica\%C3\%A7\%C3\%A3o-Digitalganha-cartilha-em-tr\%C3\%AAs-vers\%C3\%B5es > Acesso em 06/10/2014.

CEZAR, Leandro Neukirchen; ZANCHET, Aládio; PAULA, Germano de. Desenvolvimento De Pequenas Propriedades Rurais e a Utilização De Tecnologias. Disponível em: <http://www.unioeste.br/campi/cascavel/ccsa/IVSeminario/IVSeminario/Artigos/05.pdf> Acesso em 06/10/2014. 
COLAUTO, Romualdo Douglas; BEUREN, Ilse Maria. Coleta, análise e interpretação dos dados. In: BEUREN, Ilse Maria et al. Como elaborar trabalhos monoGráficos em contabilidade: teoria e prática. 3. ed. São Paulo, Atlas, 2006.

CORNACHIONE JR, Edgard B. Informática Aplicada às Áreas de Contabilidade, Administração e Economia. $3^{\circ}$ Ed. São Paulo: Atlas, 2001.

CREPALDI, Silvio Aparecido. Contabilidade Gerencial: Teoria E Prática. $5^{\circ}$ ed. São Paulo: Atlas, 2011.

CRESTANI, Verônica Viero; CRISTINA, Ada Machado da Silveira. Apropriação De Tecnologias De Informação E Comunicação No Meio Rural Brasileiro, 2011. Disponível em:<https://www.marilia.unesp.br/Home/Graduacao/PETBiblioteconomia/apropriacao-de-ticno-meio-rural-brasileiro.pdf > Acesso em 06/10/2014.

CONTERATO, Marcelo Antônio. Mercados e agricultura familiar: interfaces, conexões e conflitos, 2013.

Disponível em: <http://www.ufrgs.br/pgdr/livros/outras_publicacoes/ebooks/03_ebook_PGDR.pdf> Acesso em $06 / 10 / 2014$.

GIL, Antônio Carlos. Como elaborar projetos de pesquisa. 4. ed. São Paulo: Atlas, 2002.

GIL, Antônio Carlos. Métodos e técnicas de pesquisa social. 6. ed. São Paulo: Atlas, 2011.

INFORMATIVO TÉCNICO: Nota Fiscal Eletrônica, Ed.07, 2014. Disponível em:

<http://sistemafamato.org.br/portal/famato/informativo_completo.php?id=228> Acesso em 06/10/2014.

IPEA - Instituto de Pesquisa Econômica Aplicada. BRASIL EM DESENVOLVIMENTO: Estado, Planejamento e Politicas Público, 2010. Disponível em: <http://www.ipea.gov.br/bd/pdf/Livro_BD_vol2.pdf > Acesso em 06/10/2014.

MAÑAS, A. V. Administração De Sistemas E Informações. São Paulo: Editora Érica, 2002. MINISTERIO DA FAZENDA. Portal Da Nota Fiscal Eletrônica. Disponível em: <http://www.nfe.fazenda.gov.br/portal/principal.aspx> Acesso em 06/10/2014.

MINISTÉRIO DA FAZENDA: Portal da Nota Fiscal Eletrônica/Manual de Integração do contribuinte Versão 4.0.1, Ano 2009. Disponível em:

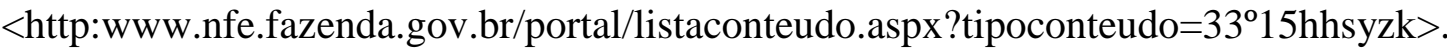

Acesso em 06/10/2014.

OLIVEIRA, Luís Martins de. Manual de Contabilidade Tributária: textos e testes com respostas et. al 10ed. São Paulo: Atlas, 2011.

OLIVEIRA, Silvio Luiz de. Tratado de metodologia científica. 2.ed. São Paulo: Pioneira, 1999.

PORTAL DA SEFAZ: Regulamento do ICMS 2014. Disponível em: 
< http://www.sefaz.mt.gov.br/legislacao/SubIndice.aspx?ID=27> Acesso em 06/10/2014.

RICHARDSON, Roberto Jarry. Pesquisa social: métodos e técnicas. 3. ed. São Paulo: Atlas, 1999.

RIR. Regulamento do Imposto de Renda (1999). Disponível em:<http://www.receita.fazenda> Acesso em 06/10/2014.

SAMPIERI, R. H. Metodologia de pesquisa. Tradução de Fatima Conceição Murad, Melissa Kassner, Sheila Cara Dystyler Cadeira. 3.ed. São Paulo: Mcgraw-Hill. 2006. 416p.

SECRETARIA DE FAZENDA DO RIO GRANDE DO SUL. O Produtor Rural E A Nova Exigência De Nota Fiscal Eletrônica. Disponível em:

$<$ http://www.affectum.com.br/affectum_site/index.php?option=com_content\&view=article\&i $\mathrm{d}=721$ :produtor-rural-e-nf-eletronica\&catid=8:noticias\&Itemid=30> Acesso em 06/10/2014.

SECRETARIA DE FAZENDA DO ESTADO DE SÃO PAULO - SP: Nota Fiscal Eletrônica. Disponível em: <https://www.fazenda.sp.gov.br/nfe/perguntas_frequentes/respostas_I.asp> Acesso em 06/10/2014.

SILVA, L. F. R.; RODRIGUES, N. K. A.; MENDES, S. B. R.; ALVES, Tiago Barbosa. Nota Fiscal Eletrônica: análise dos impactos dessa tecnologia no resultado e na estrutura organizacional das empresas, 2009. Disponível em:

<http://sinescontabil.com.br/monografias/trab_profissionais/nayara.pdf> Acesso em 06/10/2014.

SORJ, B. Brasil do povo: a luta contra a desigualdade na sociedade da informação. Rio de Janeiro: Jorge Zahar, 2003.

TATIARA, Wégela Maia Passos. Produtor Rural: Um Estudo Comparativo entre Pessoa Física e Pessoa Jurídica Agroindustrial, 2013. Disponível em:

<http://semanaacademica.org.br/system/files/artigos/artigocientificoprodutorrural.pdf> Acesso em 06/10/2015.

VERGARA, Sylvia C. Projetos e relatórios de pesquisa em administração. São Paulo: Atlas, 2006. 